\title{
Avaliação Psicológica em Varas de Família: 'ubuescas’ proteções à infância
}

Psychological Assessment in Family Courts: 'ubuescas' protections for children

Evaluación Psicológica en tribunales de família: la protección 'ubuesca' para los niños

\section{Silvia Ignez Silva Ramos}

Universidade Federal do Rio de Janeiro, Rio de Janeiro, RJ, Brasil.

\section{Pedro Paulo Gastalho de Bicalho}

Universidade Federal do Rio de Janeiro, Rio de Janeiro, RJ, Brasil.

\section{Resumo}

As reflexões presentes neste artigo partem de experiências na área da Psicologia Jurídica não apenas na Divisão de Perícias Judiciais (DIPEJ) do Tribunal de Justiça do Rio de Janeiro - mas também a partir do encontro dos autores em diversas outras instituições cuja lógica de funcionamento produz, cotidianamente, 'ubuescas' proteções, como a descrita no analisador que emerge neste manuscrito. Neste sentido, torna-se imprescindível a análise dos efeitos dos documentos escritos decorrentes de avaliação psicológica e o uso dessa ferramenta como um dispositivo disparador de verdades, que apoiam (ou constroem) as decisões nesses variados órgãos. Especificamente no estudo de caso ora apresentado percebe-se que a busca pela restituição da verdade, a produção de um mecanismo regulador para o controle das virtualidades dos sujeitos e a construção de provas materiais são centrais nas justificativas da sentença do juiz em uma Vara de Família; sobretudo por se tratar de (re)produção advinda da cientificidade afirmada em um processo de avaliação psicológica.

Palavras-chave: Avaliação Psicológica; Efeitos de Verdade; Psicologia Jurídica.

\begin{abstract}
The reflections presented in this article are based on experiences in the area of legal psychology and not only in the division of criminal investigations (DIPEJ in its Portuguese acronym) of the Court of Rio de Janeiro, as well as of meeting authors in various other institutions whose operating logic produces, daily "ubuescas" protections as described in the parser that emerges. In this sense, becomes inprecindible analysis of the effects of written
\end{abstract}


documents in current psychological assessment and the use of this tool with a trigger device truths that support (or build) the decisions in these organs varied. Specifically in the case study presented now where it is perceived that the search for the restoration of the truth, the production of a regulatory mechanism for the control of the potentialities of the subjects and the construction of physical evidence are central to the justification of the judgment the judge and a family court, especially because it is coming of scientific affirmed in a process of psychological evaluation.

Keywords: Psychological Assessment, Effects of Truth; Law Psychology

\section{Resumen}

Las reflecciones que se presentan en este articulo parten de experiencias en el area de psicologia juridica y no solamente en la division de investigaciones judiciales (DIPEJ en sus siglas en portugues) del tribunal de justicia de rio de janeiro- como tambien a partir del encuentro de autores en diversas otras instituciones cuya logica de funcionamiento produce, cotidianamente "ubuescas" protecciones como la descrita en el analizador que emerge en este manuscito. En este sentido, se torna inprecindible el analisis de los efectos de los documentos escritos de corrientes en la evaluacion psicologica y el uso de esta herramienta con un dispositivo disparador de verdades, que apoyen ( o construyen ) las desiciones en estos organos variados. Especificamente en el estudio del caso ahora presentado donde se percibe que la busqueda por la restitucion de la verdad, la produccion de un mecanismo regulador para el control de las virtualidades de los sujetos y la contruccion de evidencias materiales son centrales en las justificativas de la sentencia del juez y una corte de familia; sobretodo por tratarse de (reproduccion) viniendo de cientificidad afirmada en un proceso de evaluacion psicologica.

Palabras-Claves: Evaluacion Psicologica; Efectos de Verdad; Psicologia Juridica.

\section{Introdução}

A intenção desse artigo é problematizar os efeitos de verdade de um processo jurídico - que chamaremos de
"Ubu" - instaurado no Tribunal de Justiça do Estado do Rio de Janeiro, no começo do século XXI, e que é motivado pela separação de um casal que busca regularização de guarda da filha. 
Para contextualizar, a seção seguinte apresentará em tópicos um percurso geral do caso. A problematização do processo percorre pistas que apontam para o método da cartografia, caminho que acompanha o processo que se inicia com uma queixa de regulamentação de visita da filha e finaliza-se com uma denúncia de abuso sexual contra o genitor dessa mesma filha. A ação judicial atua como um dispositivo que produz respostas dinâmicas e que potencializa linhas de fuga singulares ao encontro da "verdade real'. O que iremos cartografar em "Ubu" é o discurso psicológico e jurídico, seus efeitos na cena e no funcionamento da decisão jurídica.

\section{"Ubu"2 e seus tópicos-imagens:}

Brasil :: Rio de Janeiro :: Início do século XXI :: Duas pessoas, paixão, gravidez, convivência, nascimento, litígio :: Um casal com uma filha, se separa :: Fórum :: Vara de Família :: Ação: Guarda/Regulamentação de Visitas :: Sistema de Garantia de Direitos :: Inquirições, 'escutas' e intervenções :: Autor: o pai biológico :: Ré: a mãe biológica :: Uma filha com três anos :: O processo :: Os advogados :: acontecimentos :: O tempo :: A sentença :: Uma Guarda Incompartilhável :: As leis ::
As normas :: As éticas :: As morais :: Os ataques :: As defesas :: O tempo :: O Conselho Tutelar :: A Delegacia da Criança e do Adolescente Vítima de Violência :: O retorno à Vara de Família :: Modificações de Cláusulas :: No mesmo processo, uma nova Ação: Violência Sexual Contra Criança :: Autora: a mãe biológica :: Réu: o pai biológico, suposto abusador :: A filha agora com quatro anos, suposta vítima :: Perícia Médica, Social e Psicológica para 'aferição do abuso sexual' :: Os advogados :: A filha do primeiro casamento é falada sem ser ouvida pela perita :: Suposta denúncia de abuso sexual contra ela também :: Falas e folhas apensam-se :: O tempo :: Um, dois...seis Psicólogos 'somam-se' ao processo :: As famílias :: As testemunhas :: 'Ubu' com mil laudas :: A criança em tela: 'fala', repete, percebe, silencia, cresce :: O Ministério Público fiscaliza :: O Juiz sentencia :: As duas filhas são consideradas vítimas de abuso pelo pai :: O Réu apela :: Segunda instância :: Sete anos se passaram :: 'Nova' Perícia Psicológica :: 'Novos' Advogados :: Reforma da sentença :: Acórdão não unânime :: Restabelecimento da sentença :: 'Ubu' é embargado na justiça e 'embarga vidas' também. 


\section{Cartografando "Ubu"}

A ideia é produzir um "textoagenciamento" que acompanha percursos, produz dados e faz conexão de redes ou rizomas. Rizoma no sentido de múltiplas entradas, sem uma metodologia rígida capaz de impor regras previamente estabelecidas. Kastrup (2009) pontua que a etimologia da palavra método - metáhódos -, significa: "predeterminado pela meta do caminho" (p. 10); a cartografia vai inverter a palavra, usando-a como hódosmeta, isto é, uma aposta na experimentação, na atitude, no compromisso com a intervenção, na criação do caminho, como acompanhar processos que estão sendo produzidos, isto é, indicar mais o que está por vir a acontecer do que o que é. Acompanhar, não representar.

Assim, o texto acompanha o processo jurídico que foi a separação conjugal e a guarda da filha desse casal e vai mostrando como esse processo vai agenciando acontecimentos a partir de dois aspectos centrais: 1) a produção da 'convicção íntima' do promotor, do juiz e da perita psicóloga a partir de suas interpretações das demandas apresentadas, e, 2) a moralização como um dispositivo presente no processo toma força de prova, fazendo o autor sentar no lugar de réu, dando sustentação à sentença.

Os tópicos-imagens já sugeriram o caminho trilhado pelo processo. Nesse momento, aproximaremos o leitor para alguns detalhes do caso para acompanharem as problematizações propostas pelos autores desse artigo.

Em razão da necessidade de se preservar o sigilo dos envolvidos, estes foram identificados por nomes fictícios. André, 46 anos, profissional renomado em sua área, divorciado, com uma filha chamada aqui de Beatriz, no início do processo com 11 anos, de seu primeiro casamento, mora em área nobre do Rio de Janeiro, próximo à sua filha Beatriz e à sua ex-mulher, já casada novamente. A exmulher, seu atual marido e Beatriz convivem harmonicamente com André.

André conhece Valentina, de 37 anos, profissional de área similar à sua, solteira e sem filhos. Apaixonam-se, passam a conviver e geram Georgia. Tudo ocorre em um ano e meio: casamento, gestação, nascimento e separação.

Especialmente a partir do nascimento de Georgia o casal convive em litígio constante, e por isso separam-se. $\mathrm{Na}$ Vara de Família (VF), no Rio de Janeiro, a separação se desenrola consensualmente.

Alguns meses depois, André retorna à VF para modificações de 
cláusula, pois a regulamentação de visitas determinada pelo juiz não acontecia, na realidade. Valentina, por problemas econômicos (parece que oriundo de um empobrecimento financeiro, comum em separações) foi morar muito longe de André e inicialmente isso justificou a impossibilidade do cumprimento dos horários para o encontro entre pai e filha. Porém, os desencontros se exacerbaram e André e Georgia não conviviam mais.

$\mathrm{O}$ retorno à $\mathrm{VF}$ produz novos lugares a André e Valentina. Esta passa a ser autora e aquele o réu no processo, pois Valentina entra com uma denúncia de abuso sexual contra Georgia, e, que seria perpetrado pelo pai, André. Esta denúncia passou a ser a justificativa dos desencontros entre pai e filha.

Um primeiro analisador: uma separação conjugal consensual; que depois, por uma reclamação do autor, pelo não cumprimento por parte da ré à determinação do juiz, a ré faz uma denúncia de abuso sexual onde a vítima é a filha de quatro anos e o suposto autor o pai, André.

Perguntas: por que essa denúncia aparece após a separação (que foi consensual)? Se houve abuso e segredo, houve cumplicidade? Há corresponsabilidade da ré? A denúncia é protetiva ou vingativa?

\section{O dispositivo escolhido}

Para entender o que é um dispositivo Deleuze (1996) sugeriu a análise foucaultiana: máquinas de fazer ver e de fazer falar. Foucault potencializou essa análise por meio de Raymond Roussel, poeta e pintor francês que compunha textos que provocavam a imaginação, sem a intenção de fazer o leitor chegar a um objetivo concreto de entendimento. Como se o poeta escrevesse imagens para desencadear uma representação única em cada leitor. Cada dispositivo porta linhas de forças enredadas em saberes e poderes sem contornos definitivos, apesar do processo judicial existir transversalizado por leis e normas que buscam circunscrever e enquadrar um acontecimento social. Porém, há algo que sempre escapa de um saber constituído e essa falha abre caminho para linhas de fuga, para mutações, como, por exemplo, 'Ubu', que foi iniciado por uma demanda de regulamentação de guarda de uma criança à época com três anos e é finalizado por uma denúncia de abuso sexual contra essa mesma criança onde autor e réu trocam de papéis e substituem os personagens. 


\section{$O$ principal analisador}

Em 'Ubu', podemos fazer variados recortes para serem problematizados. Mas o que escolhemos como principal analisador foi uma revista de entretenimento, que se tornou uma das provas centrais do processo subsidiando a sentença. Era insuficiente para condenar o réu como o autor do abuso sexual contra a sua filha, mas o bastante para colocá-lo na posição de um sujeito que poderia trazer perigo futuro e, por isso, capaz do ato da denúncia. Esse princípio que sustenta os prognósticos era o que Foucault (2001) afirmava acontecer a partir do séc. XIX: “a reforma psicológica e moral dos indivíduos é mais importante do que a defesa geral da sociedade" (p. 85).

$\mathrm{O}$ autor aponta que o grande princípio da penalidade para Beccaria era o de que "não haveria punição sem uma lei específica e sem um comportamento explícito que violasse essa lei” (p. 85). Isto é, não era crucial a infração efetiva, mas os comportamentos que poderiam estar por vir (Foucault, 2001). Descobrir este oculto, este possível de se concretizar. Em 'Ubu' a crença nessa virtualidade custou uma condenação moral e jurídica a uma das partes.

A revista de entretenimento foi o que auxiliou na identificação dos processos de produção de verdade que se efetivaram para a sentença do juiz. Problematizar o analisador como um acontecimento que produz ao mesmo tempo rupturas e novas construções para lidar com um dispositivo, que no caso em tela, era hipotético. É importante que estejamos atentos para a diferença entre denúncia e verdade; marco fundamental para a análise de qualquer denúncia de violência sexual contra crianças. Mas parece não fazer parte das reflexões em 'Ubu'.

\section{'Ubu': um processo em tempos de biopoder}

É porque as respostas do autor e do processo tornaram-se insatisfatórias para a ré - mãe da criança - que ela desdobra o processo a partir da denúncia de abuso sexual, indicando o autor, o pai de sua filha, como o perpetrador da suposta violência. O pai sai do lugar de autor e torna-se réu no mesmo processo da guarda e o foco muda.

Um adulto abusar sexualmente de uma criança (com contato físico ou sem contato físico como, por exemplo, através de exibicionismo) está previsto como crime no Direito Penal brasileiro e na Legislação da Infância e Juventude ${ }^{3}$ 
brasileira. Porém, para um ato ter status de crime, no Brasil, é preciso de prova material para transformar denúncia em 'verdade'. A denúncia está no campo da suposição, da hipótese. É necessário provar materialmente que o abuso sexual ocorreu.

Valentina então começa a apresentar as informações para construir a prova. De todas as alegações examinadas no processo, elegemos a que repetidamente aparece como prova central e que basicamente justificou a sentença do juiz. Nomeamos como dispositivo a denúncia de abuso sexual contra a criança supracitada, que teve como função fazer emergir um analisador: uma revista de entretenimento. Sentença que auxiliou na produção de subjetividade do réu, pai de Georgia, e que reforça a judicialização ${ }^{4}$ de normas sociais hegemônicas.

No primeiro momento do artigo apresentamos como o processo se inicia, seus personagens, os atores que participam do Sistema de Garantia de Direitos (SGD) e um pouco de seu desenvolvimento para dar sentido ao recorte que escolhemos analisar.

O conceito de biopoder vai nos fazer compreender como historicamente vamos construindo os instituídos sócio- jurídicos, e, por isso, não é à toa que Valentina vai construindo os sentidos para a sua denúncia e ao mesmo tempo delineando não quem é André, mas o que ele pode vir a ser. Esses sentidos são construções oriundas da transformação do poder soberano para o que Foucault chamou de anátomo-política e depois para a biopolítica, entre os séc. XVIII e XIX. A anátomo e a biopolítica são duas séries que representam o biopoder. Farhi Neto (2010) vai dizer que: “a primeira série põe em relação o detalhe, o corpo, o indivíduo, o organismo, a disciplina, a instituição" (p. 71) e a segunda série: "o global, a vida, a população, os processos biológicos, os mecanismos reguladores e o Estado" (idem).

Podemos verificar isso na demanda de Valentina onde ela utiliza os especialistas do direito e da psicologia para dar um teor de verdade à denúncia do suposto abuso. Primeiramente ela aponta o comportamento de André como suspeito, a partir de atitudes relacionadas à sua filha do primeiro casamento, Beatriz, de 11 anos. Ela demarca situações de abuso com essa primeira filha de André, Beatriz, que levaria Valentina a suspeitar que alguns comportamentos de sua filha Georgia teriam relação com o suposto abuso que seu pai estaria perpetrando contra ela. 
A revista de entretenimento de 35 páginas - alçada aqui à categoria de prova - traz alguns quadros, em duas páginas, com cenas eróticas e esta se torna uma 'revista erótica' no processo; reaparecendo várias vezes, até a sentença, como a principal prova material de indícios de pedofilia.

No processo, os operadores jurídicos apontam os significados para alguns conceitos. Transcreveremos abaixo o sentido de pedofilia, abuso sexual incestuoso e síndrome do segredo apresentados como "Razões Finais do Ministério Público":

PEDOFILIA - a palavra pedofilia vem do grego e, pode ser definida como: 'desvio sexual caracterizado pela atração por crianças e adolescentes sexualmente imaturos, com os quais os portadores dão vazão ao erotismo pela prática de obscenidades ou de atos libidinosos'. (definido por 01 (um) único autor que é Médico).

ABUSO SEXUAL INCESTUOSO - é um crime cujo início é marcado por uma relação de afeto, que pode ser físico ou de cunho só psicológico empreendida por membros da família contra outros componentes desta numa relação de dominação do mais forte, no caso o adulto, perpetrada sobre a criança ou adolescente, numa posição de dominação. (autor não especificado).
SÍNDROME DO SEGREDO - o abuso sexual é um dos segredos de família mais bem guardados e é o delito menos notificado. Envolvido pelo silêncio e compartilhado por toda a família é a principal característica da violência intrafamiliar. (definido por 01 (um) único autor que é Desembargador. Sem referências).

Os mecanismos reguladores utilizados no processo são representados pelo laudo da perita psicóloga e pela sentença.

\section{O Juiz e o Psicólogo como mecanismos reguladores do biopoder - a série da}

\section{biopolítica}

Após a separação consensual de André e Valentina, a denúncia de abuso tomou a cena do processo e o EspecialistaPerito-Psicólogo, nesse caso, foi o que deu sentido à sentença. Essa afirmação não é uma interpretação, mas uma constatação feita na leitura dos autos. Na sentença havia elogios - do Promotor e do Juiz - ao trabalho desse Especialista que fez o último laudo e que desenhou a decisão, ficando explícita a importância desse laudo psicológico para a sentença. O elogio aparece da seguinte forma: 


\begin{abstract}
PROMOTORA - Num trabalho extremamente bem elaborado e cauteloso da $2^{\text {a }}$ Perita-Psicóloga ${ }^{5}$, ela conclui decididamente seu laudo psicológico apontando firmemente acerca dos sintomas neuróticos, imaturidade afetivosexual, comprometimento de cunho perverso na esfera da identidade sexual que o leva a não se dar conta das inconveniências de certas atitudes e tratamentos dispensados as filhas, assinalando, inclusive o desejo de 'deixar uma marca em suas filhas' que elas sejam autônomas e que não tenham receio de nada.
\end{abstract}

JUIZ - [...] a realização da segunda perícia psicológica se deveu ao resultado inconclusivo da primeira perícia realizada, que não conseguiu recolher subsídios para afirmar ou negar a prática do abuso sexual. No entanto, como bem destacou a nobre Promotora de Justiça, o laudo da $2^{\mathrm{a}}$ Perícia expôs por fortes indícios que a suspeita tem fundamento [...] De forma irretocável e com utilização das mais modernas e adequadas técnicas para a realização da perícia, o Juizo analisou o incontestável laudo apresentado pela segunda perita [aqui apresenta o currículo/títulos] (grifos nosso).

O grifo no relato do Juiz é para destacar o relevo dado aos 'fortes indícios' ao ponto de fundamentar a suspeita. Lendo nos autos a primeira perícia, percebe-se um trabalho feito com cautela e fundamentação, mas foi considerado insuficiente não por uma inconsistência teórica, mas por não ratificar a 'convicção íntima' dos operadores jurídicos. Talvez tenhamos que nos perguntar para que(m) serve o laudo psicológico? Afinal, quem é responsável pela sentença?

Do início do processo até a sentença participaram seis psicólogos, entre peritos e assistentes técnicos. Como o juiz não está adstrito ao laudo psicológico e nem à equipe interprofissional do quadro ele tem autonomia para nomear quantos psicólogos achar necessário. Inclusive pode considerar partes do laudo de um psicólogo; nomeando outro pode levar em conta ambos; apenas um ou nenhum dos dois.

É importante compreendermos que há variadas possibilidades de inserção do psicólogo na Justiça: concurso público; contrato via Corregedoria; por desvio de função (um técnico judiciário que tem formação em psicologia pode ser desviado de função para trabalhar no Núcleo de Psicologia); cadastrado pela Divisão de Perícias Judiciais (DIPEJ) pelo Tribunal de Justiça do Rio de Janeiro, sem estar alocado a uma Vara exclusivamente; e por nomeação de forma autônoma e particular para um processo específico tendo seus honorários pagos pela parte que solicitou a Perícia. Nesse caso, autor e réu podem 
indicar Assistentes Técnicos (AT). Os três: o Perito e os dois ATs, devem ser da mesma carreira profissional. O Conselho Federal de Psicologia (CFP) regula essa atuação via Resolução nº 008/10.

Durante todo o encaminhamento do processo o Juiz pode nomear um psicólogo de qualquer uma das formas descritas acima e está livre para a realização de novas perícias a posteriori.

$\mathrm{O}$ mecanismo regulador que parece estar em agenciamento durante o processo é a concretização de convicção íntima por parte dos operadores jurídicos, que circunscreve a conclusão como uma profecia. O encontro do Juiz, da Promotora e da segunda perita foi como no conto de fadas a "Gata Borralheira" quando Cinderela encontra o Sapatinho de Cristal...

\section{Problematizando o laudo psicológico}

Analisaremos alguns aspectos recolhidos no laudo da segunda perícia para pensarmos o que nós, psicólogos, legitimamos em nome da proteção, do cuidado, do direito e da justiça. Os aspectos selecionados foram: 1) Os procedimentos utilizados que deram base à conclusão da perícia e à sentença; e 2) A análise dos resultados e 3) $\mathrm{O}$ encaminhamento final.
A psicologia - por meio de seu laudo - e travestindo-se como um universal legitima generalizações produzindo a norma psi e como diz Farhi Neto (2010): “(...) norma é o que pode se aplicar tanto a um corpo que se quer disciplinar, como a uma população que se quer regularizar. $\mathrm{O}$ biopoder se regulariza pela norma" (p. 71) E é por isso que Farhi Neto sugere que quando adestramos as performances individualmente (corpo, ideias) ao mesmo tempo universalizamos os resultados (estatísticas, manuais) para aplicarmos novamente depois, e o ciclo é fechado com a criação das punições aos chamados desviantes das normas. Perceberemos isso na sentença.

Inicialmente o que chama a atenção nesse laudo psicológico é que a base teórica que sustenta suas conclusões é mandatariamente realizada por meio das respostas padronizadas de 04 (quatro) testes psicológicos.

Foram realizados 11 (onze) encontros com a perita-psicóloga para aplicações de testes, entrevistas e devolução com o réu, a autora e a filha, de três anos, do ex-casal ${ }^{6}$.

A perícia foi determinada por uma Juíza de Vara de Família. Já havia sido realizado um Laudo Psicológico, fruto de uma primeira perícia, e dois Pareceres (sobre o laudo da perita) de duas 
psicólogas que atuaram como Assistentes Técnicas (AT) do ex-casal. A primeira perícia foi considerada inconclusiva e por isso houve a determinação de uma segunda perícia, como fora anteriormente relatado.

O procedimento utilizado foi a aplicação de testes e a utilização das respostas padronizadas compondo a escritura do laudo psicológico final. Muitos vocábulos supostamente teóricos ficaram sem explicação; dado importante, pois o destinatário do laudo é um profissional de outro campo de saber - o juiz. Mesmo para um profissional do campo psi, no Código de Ética Profissional, Resolução no 010/2005, está instituído em seu Art. $1^{\circ}$, g), que deve-se "informar, a quem de direito, os resultados decorrentes da prestação de serviços psicológicos, transmitindo somente o que for necessário para a tomada de decisões que afetem o usuário ou beneficiário", (Conselho Federal de Psicologia, 2005) e, a Resolução no 007/2003 que dá as diretrizes para elaboração de documentos em Psicologia determina também que o psicólogo deve evitar "a diversidade de significações de linguagem popular, considerando a quem o documento será destinado" (Conselho Federal de Psicologia, 2003).

Muitas vezes, sob o manto do discurso científico, muitos enunciados suscitam no leitor reflexos do significado de senso comum, deturpando o sentido dos conceitos empregados. Por exemplo: 'perversão', na linguagem popular, encobre-se de um sentido que não existe para a Psicanálise. Mesmo para a Psiquiatria as classificações atuais pautamse a partir de outros termos, a fim de alcançar maior precisão ${ }^{7}$; apesar de que, historicamente, o termo foi utilizado de diversas formas.

Sem a pretensão de realizar um levantamento completo, podemos mencionar alguns dos termos ou enunciados utilizados no laudo: 'esquizoidia', 'capacidade de síntese afetada,'diminuição da abertura para os relacionamentos', comportamento inautêntico ou profundo, 'funções egóicas de planejamento, previsão e organização prejudicadas', 'mecanismos de contenção insuficientes', '[pessoa] sujeita a descontroles', 'denota insegurança, indecisão e dubiedade', 'personalidade egocentrada', 'voracidade, reduzida capacidade inibitória', 'vivências angustiosas [que] podem favorecer passagens ao ato', 'sexualidade com conflitos', 'problemas na identidade sexual', 'condutas de cunho perverso parecem se desenvolver no contexto de busca de um prazer superior', 'maturidade 
emocional imperfeita', 'imaturidade afetivo-sexual', 'comportamentos e atitudes neuróticas'.

Ainda na Resolução do CFP $n^{\circ}$ 007/2003 encontramos: "Torna-se imperativo a recusa, sob toda e qualquer condição, do uso dos instrumentos, técnicas psicológicas e da experiência profissional da Psicologia na sustentação de modelos institucionais e ideológicos de perpetuação da segregação aos diferentes modos de subjetivação”. E ainda afirma que qualquer documento produzido por psicólogo "deve considerar a natureza dinâmica, não definitiva e não cristalizada de seu objeto de estudo" (Conselho Federal de Psicologia, 2003).

Na medida em que a Psicanálise é suscitada como referência teórica da segunda perita é importante sublinhar que o estabelecimento de diagnóstico não costuma ocorrer em pouco tempo nessa linha e que 'neurose' e 'perversão' não são patologias para a psicanálise. São estruturas psíquicas, modos de estruturação da subjetividade, as quais, por si só, não são boas ou más. É questionável se o diagnóstico simultâneo de neurose e perversão pode ser realizado e fica a pergunta: o que seria a 'busca de um prazer superior' para a Psicanálise? E para a Psicologia? Pergunta que não quer calar em 'Ubu'.
Sobre esse aspecto, devemos nos interrogar se a sentença não revelaria a cristalização de uma versão que não foi comprovada objetivamente e que subjetivamente estaria marcada pelas supostas imprecisões que mencionamos acima.

Outro ponto a ser problematizado é quando o laudo aponta afirmações e encaminhamentos, por parte da perita, sem a mesma ter atendido as pessoas a quem se refere. Nesse caso ela fala de Beatriz (primeira filha) e da ex-mulher do réu levantando hipóteses por intermédio do laudo da primeira perita e por esclarecimentos da outra parte - a autora (!), mas não por atendimento presencial. Cogitar que mãe e filha têm necessidade de atendimento psicológico com base exclusivamente em relatos de terceiros não parece ser um procedimento considerado adequado no campo psi.

Por fim, a prova central nesse caso envolveu uma revista de entretenimento que, por apresentar algumas cenas sensuais, foi interpretada como inadequada para o réu ler com sua filha Beatriz, que à época tinha 11 anos. Essa revista aparece no processo para a surpresa de André, pois Valentina não comunicou ao mesmo que a levaria, ao se separarem. A tal revista apoiou a sustentação jurídica de que André 
apresentava 'problemas de ordem moral', pois foi interpretado que um pai não deveria presentear a filha de 11 anos 'com uma revista como aquela', que muda de nome no processo sendo indicada como uma revista erótica, como se ela por inteiro tratasse de tema sexual. Essa revista foi considerada como forte indício de que algo havia acontecido, mas como não houve prova material sobre o abuso sexual, o Juiz trabalha com a possibilidade do que poderia vir a acontecer. Abaixo alguns trechos onde os operadores jurídicos falam da revista:

PROMOTORA $-[\ldots]$ a Revista de
Entretenimento, com cenas de
homossexualismo e sadismo, adquirida
pelo pai, com certeza não foi encontrada
na seção Infantil da livraria. Basta uma
pesquisada na internet. Assim, data vênia,
não cabe aqui se acolher a tese da surpresa
ou do desconhecimento do pai ao se
confrontar com as imagens eróticas.

JUIZ - $[\ldots]$ Todas as circunstâncias colhidas, como a utilização, pelo pai, da revista com conteúdo obsceno [...] são assustadoras, se levarmos em conta que o material foi presenteado pelo genitor a uma menina de 11 anos, que deveria se protegida pelo mesmo [...].

A sentença encarna a convicção íntima do Juiz julgando como improcedente a solicitação de Guarda Compartilhada, por parte do pai, usando como mecanismo regulador a visita assistida até a maioridade da criança para protegê-la das virtualidades do genitor, isto é, do que ele pode vir a fazer. Foucault (2001) aponta que a penalidade a partir do século XIX queria controlar nem tanto o que os sujeitos fizeram, ou o 'nível de sua periculosidade', mas o que os sujeitos poderiam vir a fazer, do que seriam capazes de fazer, do que estariam na iminência de fazer - suas virtualidades. Já que “[...] ninguém é suspeito impunemente. $\mathrm{O}$ mais ínfimo elemento de demonstração ou, em todo caso, certo elemento de demonstração, bastará para acarretar certo elemento de pena" (Foucault, 2002, p.10) encontrou-se uma forma de condenar sem provas. Desse modo, o pai é condenado a conviver com sua filha por meio de visitas assistidas. Não só auxilia na decisão a 'revista erótica', mas o 'caráter perverso do autor' que se tornou réu, porém, nesse momento como em um ato falho, a sentença deixa escapar o lugar inicial do pai. De autor tornou-se réu. E sem prova, foi alienado parentalmente, pelo Juiz, por meio de uma condenação moral:

[...] São necessários alguns indicadores e não apenas um só para que se tenha plena 
certeza da existência do abuso. Por tal, após bem analisar todo o processo e a ampla prova produzida, o Juízo está convicto de que o autor, infelizmente, possui sérios distúrbios de ordem sexual, e a criança está a necessitar da proteção, de modo a ser exposta às práticas abusivas que possam vir a ser praticadas, tudo em virtude da doença que seu genitor é portador, e que lhe causariam prejuízos irreparáveis. Essa é a única medida possível e adequada a ser tomada, para livrar a menor da indevida exposição, e para que não fique sujeita a toda sorte de acontecimentos [...]. (grifos nossos)

Ubu é encerrado com agradecimentos e elogios: “[...] Essa serventia agradece o primoroso e relevante trabalho dessa ilustre perita-psicóloga, prestado ao judiciário, essenciais para a elucidação do caso.”

\section{Considerações Momentâneas: 'Ubu' instituiu uma vigilância}

Martelo batido. Sentença prolatada. Para estar com a sua filha, o pai, André ${ }^{8}$, terá a presença de um panóptico ${ }^{9}$ ambulante, representado por alguém que vigia as visitas. Instituída como 'visita assistida' chamaremos aqui de visitapanóptica, que contraria - em nome da proteção e do cuidado - os tratados nacionais e internacionais sobre Infância e
Juventude que ressaltam a importância da convivência familiar.

A Lei Nacional de Adoção (LNA/09), Lei de $\mathrm{n}^{\circ} 12.010$ de 03 de agosto de 2009, que altera o Estatuto da Criança e do Adolescente (ECA/90), Lei $n^{\circ} 8.069$ de 13 de julho de $1990^{10}$, tem como um de seus eixos centrais a discussão sobre a importância da convivência familiar.

O Código Civil Brasileiro, Lei $\mathrm{n}^{\circ}$ 10.406 de 10 de janeiro de $2002^{11}$, sofreu alteração em seus artigos $n^{\circ} 1583$ e 1584 , em 13 de junho de 2008, sancionando o novo instituto de Guarda Compartilhada, na intenção de fazer funcionar a convivência com ambos os pais. Retira-se assim, o pai (na maioria das vezes a mãe é a guardiã principal e o pai fica com o filho de 15 em 15 dias) do lugar de visitante. Visitação nada tem a ver com convivência. Vínculo não se constrói com visitas, mas com frequência que é o que significa convivência em seu sentido denotativo. Brito (2005) aponta:

\footnotetext{
A familiaridade com o outro não é dada a priori ou apenas por meio de um sobrenome comum, mas é o resultado de uma construção, solidificada em um processo contínuo, regular. De forma semelhante, "trato diário" não pode ser equiparado a visitas quinzenais (p. 67).
} 
Também não é por acaso que o Código Civil muda o nome do instituto de pátrio poder para poder familiar. Reafirma desse modo que os deveres e direitos em relação ao filho estão relacionados aos dois responsáveis pela criança. Dessa forma, põem-se em questão os conceitos historicamente naturalizados de 'instinto materno', ‘amor biológico', ‘mãe cuidadora', 'pai provedor', entre outros.

(Des)encaminhamos o artigo para falar de guarda compartilhada e poder familiar, pois perecebe-se sutilmente que em nome da proteção, por um supostoabuso-que-poderá-vir-a-acontecer, autoriza-se a reencarnação de institutos obsoletos como o da visitação de 15 em 15 dias desconstruindo, desse modo, o movimento instituinte da guarda compartilhada. São recuos sutis que desconstroem os movimentos sociais tão batalhados no campo da família ${ }^{12}$.

$\mathrm{O}$ efeito da interpretação de que a revista de entretenimento é uma revista erótica constrói em 'Ubu' uma dupla sentença que percebemos na reiteração do Ministério Público ao sugerir um suposto novo abuso sexual, não referente à criança em tela do processo, Georgia, mas a vítima seria a outra filha, Beatriz ${ }^{13}$, que apesar de não ter sido atendida pela segunda perita, esta produz uma conclusão baseada na perspectiva do 'risco' ${ }^{\text {, }}$. Por essa segunda virtualidade a sugestão do Ministério Público foi:

\begin{abstract}
Reitero ainda que sejam extraídas dos autos as seguintes peças: iniciais, contestações, réplicas, depoimentos pessoais dos litigantes, informantes e testemunhas, ata da ACIJ, os dois laudos periciais e esclarecimentos: à cópia do livro erótico, à cópia do acordo de visitação, devendo ser encaminhados a Central de Inquéritos [Vara Criminal] para apuração, em tese, do delito criminal praticado em face da filha Beatriz e para o Juizado da Infância e Juventude para aferição da necessidade de instauração de procedimento próprio na preservação da integridade física e emocional da menor Beatriz. (grifos nossos)
\end{abstract}

O motivo de chamarmos o processo de 'Ubu' foi inspirado em Foucault (2002), quando no livro 'Os Anormais' ele aponta o cruzamento entre os enunciados científicos e jurídicos usados para legitimar como estatuto de verdade a produção desses discursos que estão alheios às próprias regras científicas e jurídicas. Por isso são: Textos grotescos - e quando digo
'grotesco' gostaria de empregar a palavra
num sentido, se não absolutamente estrito,
pelo menos um pouco rígido ou sério.
Chamarei de 'grotesco' o fato, para um
discurso ou para um indivíduo, de deter
por estatuto efeitos de poder de que sua 
qualidade intrínseca deveria privá-los. O grotesco ou, se quiserem, o 'ubuesco'15. (p. 15)

\section{Notas}

1 Propositalmente o motivo da escolha desse nome será explicado apenas ao final deste artigo.

2 Todos os significantes com aspas, encontrados nessa seção, apontam para uma dúvida e/ou ironia ao seu sentido instituído.

${ }^{3}$ Código Penal Decreto-Lei N. ${ }^{\circ} 2.848$, de 07 de dezembro de 1940, Título VI - Dos Crimes contra a Dignidade Sexual; Capítulo I - Dos Crimes Contra a Liberdade Sexual; Capítulo II - Dos Crimes Sexuais Contra Vulnerável (Redação da Lei no 12.015/07.08.2009) e o Estatuto da Criança e do Adolescente (ECA/90) Lei n 8.069/90 Art. 130.

${ }^{4}$ É a lógica do judiciário que se propaga para outros campos da vida.

${ }^{5}$ Houve o trabalho de outra Perita que o juiz não considerou seu laudo por ser "inconclusivo".

6 Não estaremos aqui avaliando se a quantidade de atendimentos foi adequada ou não, pois isso depende de cada caso e da metodologia utilizada. Estamos mencionando apenas para compor a descrição do atendimento.

${ }^{7}$ Ballone, G.J. Delitos Sexuais (Parafilias). In: PsiqWeb, Internet. Disponível em www.psiqweb.med.br. Acesso em 10.08.12.

8 André apela para a segunda instância, consegue a reforma da sentença, mas Valentina entra com "Embargos Infringentes" e a sentença de primeira instância é retomada. Do início ao fim do processo o tempo é de sete anos.

9 Foucault (1984) vai sugerir que o Panóptico de Bentham - uma construção em anel; no centro, uma torre; esta é vazada de largas janelas que se abrem sobre a face interna do anel; a construção periférica é dividia em celas, cada uma atravessando toda a espessura da construção "[...] Basta então colocar um vigia na torre central e em cada cela trancar um louco, um doente, um condenado, um operário ou um escolar [...] A plena luz e olhar um vigia captam melhor que a sombra, que finalmente protegia. A visibilidade é uma armadilha”. (p.62)

10 Disponível em: http://www.planalto.gov.br/ccivil_03/leis/l 8069.htm 
em:

http://www.planalto.gov.br/ccivil_03/leis/2 002/L10406.htm

12 Para mais informações visite: http://www.apase.org.br/

13 Pela morosidade da justiça, Beatriz nunca foi chamada pela Vara da Infância, Juventude e do Idoso. Com isso, o feito tornou-se extinto, pelo alcance da maioridade.

14 Este conceito é trabalhado em muitas pesquisas no campo da Infância na Psicologia e no Direito. Não trabalharemos aqui.

15 O adjetivo "ubuesco" foi introduzido em 1922, a partir da peça de Alfred Jarry, Ubu roi, Paris, 1896. Ver Grand Larousse, VII, 1978, p. 6319: “Diz-se do que, por seu caráter grotesco, absurdo ou caricato, lembra o personagem Ubu"; Le Grand Robert, IX, 1985, p. 573: "Que se assemelha ao personagem Ubu rei (por um caráter comicamente cruel, cínico e covarde ao extremo)".

\section{Referências}

Brito, L.M.T. (2005). Guarda compartilhada: um passaporte para a convivência familiar. Guarda compartilhada: aspectos psicológicos e jurídicos. Porto Alegre: Equilíbrio, 53-71.

Conselho Federal de Psicologia. (2003). Resolução CFP 007/03 - Institui o Manual de Elaboração de Documentos escritos produzidos pelo psicólogo, decorrentes de Avaliação Psicológica e revoga a Resolução CFP 017/02. . (2005). Resolução CFP 010/05 Aprova o Código de Ética Profissional do Psicólogo.

Deleuze (1996). O que é um dispositivo? $O$ mistério de Ariana. Tradução e prefácio de Edmundo Cordeiro. Lisboa: Vega-Passagens.

Farhi Neto, L. (2010). Biopolíticas: as formulações de Foucault. Florianópolis: Cidade Futura.

Foucault, M. (2001). A Verdade $e$ as Formas Jurídicas. Rio de Janeiro: Nau.

. (2002). Os Anormais. São Paulo: Martins Fontes.

Kastrup, V.; Barros, R.D.B. (2009). Movimentos-funções do dispositivo na prática da cartografia. Passos, E.; Kastrup, V.; Escóssia, L. Pistas do método cartográfico: pesquisaintervenção e produção de 
subjetividade. Porto Alegre: Sulina, 76-91.

Silvia Ignez Silva Ramos-
$\begin{aligned} & \text { Discente do curso de } \\ & \text { Programa de }\end{aligned}$ de Poutorado do
Psicologia da Universidade Federal do Rio
de Janeiro.
E-mail: psilig@ gmail.com

Pedro Paulo Gastalho Bicalho- Doutor em Psicologia, Professor do Instituto de Psicologia e do Programa de PósGraduação em Psicologia da Universidade Federal do Rio de Janeiro. Jovem Cientista do Nosso Estado (FAPERJ).

E- mail: ppbicalho@ufrj.br 